\title{
Commentary on Study of Contemporary Integrative Thinking
}

\author{
Jian Wang \& Juan Hu \\ Institute of politics and laws, Ludong University \\ Yantai 264025, Shandong, China \\ E-mail: wangjian0501@163.com
}

\begin{abstract}
Contemporary integrative thinking is an important thinking way of current scientific development. It is continually developed with flourishing of holism, systematic science and complexity theory. It is far from enough the study of academic circles on its theoretical system, and an automatic condition exists in some aspects. This article is going to comment and analyze several important aspects in theoretical establishment of contemporary integrative thinking. Then the authors make clear study venation of the academic circles, and meanwhile, propose instructive opinions about the theoretical groundwork, scientific essence and practical application of contemporary integrative thinking.
\end{abstract}

Keywords: Integrative thinking, Contemporary integrative thinking, Scientific thinking way

\section{Rise of study on contemporary integrative thinking}

Integrative thinking is a brilliant thinking flower born in the earlier human society, and guides human beings in their creation of illustrious ancient civilization with its unique intelligent fascination. Under the direction of integrative thinking, it is necessary that people lay an eye on integrity in their way of understanding and controlling the world, and that they attach importance to synthesis. However, since its birth, the simplicity thinking of western modern science in the emphasis on analysis and regression and negligence on synthesis and integrity is leading in natural science, and has invaded the territory of human science several times. At the beginning of the $20^{\text {th }}$ Century, establishment and development of the theory of relativity and quantum mechanics increasingly disclosed limitations of simplicity thinking, while the complexity science later was just proposed and developed on the basis of criticizing the simplicity thinking. Meanwhile, the latter also revealed the prologue of study on contemporary integrative thinking.

\section{Status quo of study on contemporary integrative thinking}

\subsection{Study on the concept of contemporary integrative thinking}

Contemporary integrative thinking, namely, is integrative thinking's brand-new pattern in the current situation. Although scholars in academic circles rarely apply the phrase of "contemporary integrative thinking", study achievements of the brand-new pattern of integrative thinking in the current situation are obvious.

There are approximately three viewpoints about this subject in academic circles. Firstly, contemporary integrative thinking is identified as a systematic thinking, such as "systematic thinking or integrative thinking is a fundamental way of contemporary scientific thinking." "To understand a system, it is necessary to lay an eye on the integrity, and to establish an integrative thinking way of the system, or a specific and integrative thinking way" etc. Scholars holding this viewpoint believe that, the task of general system theory is to scientifically explore "wholeness" and "integrity", and the core of systematic thinking is wholeness and integrity. Therefore, in order to bring into prominence this feature of systematic thinking, the two concepts of "integrative thinking" and "systematic thinking" are mixed together.

The second viewpoint is to attribute contemporary integrative thinking to one aspect within the framework of systematic thinking or complexity thinking, so as to endow it with a definite implication, namely, "integrative thinking is a thinking way which applies an integrative concept to recognize an object, to ponder over a matter and to sort out the thought." Integrative thinking starts from integrity, conducts comprehensive and overall thinking in the system, structure, level (part), function, organization, information, contact means, and external environment etc, and reveals and grasps the entire characteristics and overall rules of the system. In his study on complexity thinking, Peng Xinwu also points out characteristics of contemporary integrative thinking as a thinking perspective, namely, "to watch the world with an integrative view", "to directly resort to the wholeness, and to understand the wholeness by means of study on the property and structure of the wholeness", "understanding in wholeness of an object itself contains understanding in 
part which constitutes the object", "at the time when part of an object is understood through wholeness of the object, the wholeness can also be understood through its parts", etc. All in all, according to this viewpoint, contemporary integrative thinking is to understand relation between factors and the system and environment in a dialectical and unified way, so as to further grasp the entire features of the system.

The third viewpoint is to attempt to study contemporary integrative thinking as an independent thinking way. Some scholars are committed to determining contemporary integrative thinking on the theoretical basis of systematic philosophy. They believe that, faced with complexity of current natural, human and global development, integrative concept, as a subordinate concept of the systematic concept, cannot adapt to changes in both theory and practice. Therefore, theoretical status of contemporary integrative thinking should be escalated, but its relation with systematic theory hasn't been clearly recognized. Besides, some scholars hold the view that contemporary integrative thinking is "a thinking framework and method based on contemporary spirit", and so consider the systematic theory merely one aspect of the theoretical foundation. They generally point out that, contemporary integrative thinking has such characteristics as "systematicness", "openness", "unitarity", and "predictability", etc, and the soul of contemporary integrative thinking is the insight of overall importance, integrity, dialectures, sustainable existence and sustainable development. The key is to grasp the overall situation and wholeness in an authentic, specific and procedural way. This viewpoint provides broader field of vision for contemporary integrative thinking, but achievements of its study are rare.

\subsection{Theoretical illustration of contemporary integrative thinking}

\subsubsection{Features of contemporary integrative thinking}

There are various opinions on study on features of contemporary integrative thinking in academic circles. Which features on earth it has, whether it has a fundamental feature, and how these features can be expressed --- answers to these issues are difficult to get unified, but more or less certain consensus is exhibited.

Generally speaking, contemporary integrative thinking includes the following six features.

Firstly, the feature of overall importance of contemporary integrative thinking means that, when people perceive an object or phenomenon, they should regard it as a dialectical and unified "overall situation", "system" and "entirety" of whole and parts. They should attempt to grasp all details as possible as they can, and then combine these details in an organic way so as to realize "scientific" cognition of its completeness. Just as Lenin said in his $<<$ Note on Philosophy >>, we should not only focus on "decomposition" of all parts, but should grasp "sum of all these parts". This has obviously highlighted the dialectical thinking of unity and oppositeness of whole and parts, and has overcome the big mistake in traditional thinking which merely concentrates on whole but ignores parts.

Secondly, interrelation feature of contemporary integrative thinking refers to that, as an object and phenomenon of the cognition target, its components are in a state of inseparable, non-linear and inconsecutive interaction. This kind of "interaction" is so inseparable that people cannot ignore it in their cognition. Otherwise, they have no means to obtain an integrative cognition in the objects. However, academic circles' understanding in this non-linear relation "inevitably stops over a conceptual, and even general or blurry level". An in-depth cognition is not only a philosophical issue, but more with a property of "specific analysis for specific problem".

Thirdly, nondeterminacy of contemporary integrative thinking refers to that, it is impossible to have an accurate and purely objective cognition in the object and phenomenon, so only a probability or statistical description is possible. Theoretical foundation of nondeterminacy of contemporary integrative thinking derives from the "demarcation of subject and object" in quantum mechanics. Heisenberg believes that in the observation process of quantum, because physical links between boundaries of observed system and measuring apparatus can be described without ambiguity, quantum mechanics law only indicates the statistical property nearby the boundary. Possibility of statistical internal links is merely caused by uncontrollable interference of regarding effect of measuring apparatus on observed system as part. He takes the example of photographic quantum theory of Wilson cloud chamber, and believes that, "here we immediately encounter the randomicity in the observation concept already mentioned, that is, to classify ionized molecules into the observed system or to regard them as observation apparatus, this is purely a matter of convenience". Therefore, quantum mechanics can only make a probability description of a single object.

Fourthly, openness of contemporary integrative thinking means that, when people recognize an object and phenomenon, they should not only grasp its internal components and interrelation, but should not ignore its external environment, because internal and external combination can achieve integrative cognition. According to system theory, the entire world is a grand system constituted by interactional things on earth. Not only exchange and communication of substance, energy and information exist among factors within a single object, but also this object communicates with its external environment, so as to maintain a dynamic balance as a whole.

Fifthly, predictability of contemporary integrative thinking means that, when people cognize an object and phenomenon, they should attempt to make definite prediction on its changes in the nearest future based on what they know. This feature comes from the basic need of people to try to cognize the world and transform it, and is targeted at dynamic 
chanciness that is difficult to grasp in the cognitive process. The nondeterminacy aforementioned has resulted in bankruptcy of absolute determinism, and chanciness and randomicity occurrences in the natural and human society have been pulled back from the borderland of scientific research. In face with so much chanciness and randomicity, people have, for a time, suspected whether causal connection in classical science still has its value. However, the future is not completely unpredictable. Otherwise, people have no way to make an action.

Sixthly, unitarity of contemporary integrative thinking means that, as the target of cognition, an object and phenomenon is not purely objective. They are essentially personalized natural kinds, and they are within the whole connection of the nature and human being who regards practice as an intermediary agent. Therefore, in the cognitive process, human being is not only a subject, but also an object. Furthermore, the practical character of scientific research is brought into prominence, so human being is not merely a "tool" of cognition, but also a purpose of cognition.

Among the above six features, it is generally believed that, overall importance is the fundamental feature of contemporary integrative thinking, and other features can be deduced based on this fundamental feature. Of course, some scholars focus more on its interrelation feature, and hold the view that it is a venation and "clue" which combines parts into a whole in an organic way, while thinking mode of modern mechanicalness reductionism ignores that point. Therefore, nonlinearity, the symbol of contemporary scientific thinking, is also an inference familiar to people for a long time.

\subsubsection{Theoretical and practical significance of contemporary integrative thinking}

Theoretical significance of contemporary integrative thinking is especially reflected in the fact that, as a primary scientific thinking mode, it continuously promotes research direction of scientific methodology and assessment towards a rational integration of science and humanity. Of course, as a renewed contemporary explanation of ancient integrative thinking which is an immemorial human wisdom flower, contemporary integrative thinking also exhibits inheritance, enrichment and promotion of civilized fruits of human thinking, and is helpful to initiate new civilization of human thinking in a new era.

Each progress of human beings' existence and development requires that they have a new thinking mode, and likewise, development of thinking mode affects their existence and development. It ought to be said that, in daily living, or in production practice and social and political practice, and especially in scientific and technical practice, integrative thinking will play an indispensable and significant role.

\subsection{Application study on contemporary integrative thinking}

Any thinking way has its intentionality in essence. As a scientific thinking mode in the new era, contemporary integrative thinking plays its powerful practical function once it is brought into birth. However, theoretical study on contemporary integrative thinking by academic circles is not systematic, and is often mixed with study on complexity thinking mode, so study on its application is seldom conducted.

Generally speaking, academic circles tend to carry out reflection of contemporary integrity on some macro issues, such as environmental protection, ecological problem, sustainable development, construction of harmonious society and development of human being, etc. $<<$ Complexity Thinking and Social Development $>>$ by Peng Xinwu is a representative works, in which he conducts a specific philosophical observation on relevant issues concerned with social development from the perspective of complexity thinking, and opens up people's field of vision. Several articles by Chen Lizhong on sustainable development, construction of harmonious society and scientific outlook on development are also typical contemporary integrative thinking. In his $<<$ All-round Development: the Integrate Category of Relationship between Human Beings and Society >>, Fu Zhiyong makes more attempts.

\section{Prospects of study on contemporary integrative thinking}

By analyzing achievements of study on current contemporary integrative thinking, we think that the following several issues are still open to be further studied.

\subsection{To expand study on groundwork of contemporary integrative thinking theory}

Scholars are usually confined to systematic science itself in their study on groundwork of contemporary integrative thinking theory. Even if some scholars transfer their field of vision to such theories as Post-modernism and Structralism etc, most of them are limited to comparative study and analysis in these theories and integrative thinking, but haven't absorbed instructive ingredients of "others", as a result of which further study is restricted.

With development of holism and complexity study, dialectical holism has become a significant issue in the front field of contemporary academic research. This kind of holism is a holism of scientific morphology of philosophy, which not only absorbs advantages and abrogates disadvantages of existing holism, but also comprehensively studies front achievements of modern science, new experiences of current social practices and basic historical experiences of scientific and cognitive history. It should be pointed out that, with advancement of study on dialectical holism, the theoretical groundwork of study on integrative thinking will be greatly enriched. 


\subsection{To further explore scientific essence of contemporary integrative thinking}

Contemporary integrative thinking is not merely a simple development of ancient integrative thinking, and is not only more enriched in terms of its form and more precise in terms of its structure, but also a transformation in terms of essence. It is a product of deep reform of natural science theoretical paradigms, and is an outcome of deep integration of such transversal subjects as systematic science and complexity theory with Marxism's dialectical thinking. It concentrates on qualitative research, but not short of quantitative analysis, especially organic combination of these two methods. Therefore, in essence, it is a scientific thinking mode. Further grasp of the scientific essence of contemporary integrative thinking helps make clear direction of advance of its theoretical research, and helps avoid detours.

\subsection{To strengthen study on application of contemporary integrative thinking in practice}

Application of contemporary integrative thinking in practice is the ultimate goal of its study, and is also a powerful motive to check its truth and to break through itself. The recently developed STS, artificial intelligence research and complexity theory, as well as integrative phenomena in the society provide broad space for application of contemporary integrative thinking. Therefore, study by linking contemporary integrative thinking with these application fields can, on one hand, gets theoretical support from these fields, and can, on the other hand, enable contemporary integrative thinking to be practically supported, corrected and further improved in its application.

\section{References}

Ervin Laszlo. (1998). Introduction to Systems Philosophy, translated by Qian, Zhaohua, et al. Beijing: Commercial Press, preface.

Feng, Guorui. (2008). On Adhering to the Dialectical Holism. Journal of Beijing Administrative College, 6:96.

$\mathrm{Fu}$, Zhiyong. (2002). All-round Development: the Integrate Category of Relationship between Human Beings and Society. Journal of Northwest University (Philosophy and Social Sciences Edition), 3:87.

Lenin. (1956). Note on Philosophy. Beijing: People's Publishing House, 239.

Liu, Feng. (2001). An Outline of Systematic Thinking Mode. Journal of Shanghai Jiaotong University (Philosophy and Social Sciences), 4:13.

Miao, Dongsheng. (2005). On Systematic Thoughts (Third). Journal of Systemic Dialectics, 1:1.

Peng, Xinwu. (2003). On Complexity Research Way. Journal of Systemic Dialectics, 1:14-15.

Qiao, Ruijin. (2000). On Nonlinear Dialectical Characteristics of Contemporary Integrative Thinking. Journal of Systemic Dialectics, 3:1.

Wang, Tiansi. (1998). Introduction to Micro Epistemology. Nanchang: JiangXi People's Publishing House. 135, 297.

Xia, Jianhua \& Xu, Zheng. (2004). Systematic Explanation of Holism Idea. Journal of Systemic Dialectics, 2:25.

Xing, Yuan. (1999). On Integrative Thinking and Sustainable Development. Journal of Systemic Dialectics, 2:9.

Zhang, Zexing. (1995). Scientific Development and Integrative Thinking Mode. Studies in Dialectics of Nature, 11: Supplement. 